\title{
Applicability of fiber Bragg grating sensors for cure monitoring in resin transfer molding processes
}

\author{
Yannick Blöß1 ${ }^{1 *}$, Gergely Hegedüs ${ }^{2}$, Gábor Szebényi ${ }^{2}$, Tamás Tábi ${ }^{2,3}$, Ralf Schledjewski ${ }^{1}$, \\ Tibor Czigany, 3 \\ ${ }^{1}$ Processing of Composites Group, Department Polymer Engineering and Science, \\ Montanuniversität Leoben, Leoben, Austria \\ ${ }^{2}$ Department of Polymer Engineering, Faculty of Mechanical Engineering, \\ Budapest University of Technology and Economics, Budapest, Hungary \\ ${ }^{3}$ MTA-BME Research Group for Composite Science and Technology, Budapest, Hungary \\ *Corresponding author: yannick.bloess1@unileoben.ac.at
}

Keywords: Fiber Bragg grating (FBG) sensor, Thermosetting resin, Cure monitoring, Resin transfer molding (RTM)

\begin{abstract}
This paper examines the use of Fiber Bragg Grating (FBG) sensors for cure monitoring purposes in Resin Transfer Molding (RTM) processes. Within an RTM test series a thermoset epoxy-amine resin system was used in combination with a woven flax fiber reinforcement. Particular attention was paid on the location of the optical fiber sensor and its sensitive Bragg grating element inside the mold cavity. Three different installation approaches were tested and the correlation of the corresponding strain response with the actual cure state of the resin system was investigated at $50{ }^{\circ} \mathrm{C}$ and $70{ }^{\circ} \mathrm{C}$ isothermal cure temperature, respectively. We could demonstrate that characteristic, conspicuous strain changes are directly related to the sol-gel-conversion of the thermoset polymer, which was analyzed considering different approaches for the gel-point detection based on rheological measurements. With the installation of the sensor inside a controllable, capsuled resin volume, we could achieve the most reliable strain response that provides capabilities to give in-situ information of the cure state beyond the gelation point.
\end{abstract}




\section{INTRODUCTION}

The manufacturing of fiber-reinforced composites using Liquid Composite Molding (LCM) processes has been established as one of the main techniques for the production of resilient structural parts ${ }^{1}$. Such processes are often influenced by interconnected process inputs affecting the impregnation of the reinforcing textile structure and the irreversible cross-linking reaction of the thermoset polymer. Unsuitable process parameters and defective process control results in potential quality problems for the final composite, like an incomplete impregnation, a poor surface quality, an under-cured resin or unnecessarily excessive cycle times ${ }^{2}$. Such sophisticated process technologies can be improved in terms of quality and reliability when meaningful in-situ data can be obtained during the process. Various in-line sensor technologies and applications have already been developed and discussed for monitoring applications ${ }^{3,4}$. One group of sensors is represented by optical fibers, which uses in general optical interferometric effects. One of the most cited and used optical fiber sensors for measurement and monitoring tasks in connection with polymer composites is the Fiber Bragg Grating (FBG) sensor ${ }^{5}$. That is likely due to specific advantages, as they provide a simple design, a small size and are suitable for integration into composite materials with minimal perturbation to the reinforcing fibers ${ }^{6}$. FBG sensors are coated, optical fibers with a usual total diameter of $100 \sim 200 \mu \mathrm{m}$. A Bragg grating means physically a pattern of alternating fiber sections with high and low refractive indices typically within a length of $1 \sim$ $20 \mathrm{~mm}$, which reflects a defined wavelength of a light spectrum guided into the fiber ${ }^{7,8}$. An optical interrogator is used as light source and measurement device for the reflected wavelengths. Applied strain in the FBG sensor leads to an elongation or compression of the grating pattern and therefore to a wavelength shift. Thus, the FBG sensor is suitable for measuring the actual strain at the Bragg grating locations that is caused by mechanical external loads or by thermal expansion or contraction due to temperature changes. Doyle et $a l^{6}$ presented in their study an overview of optical fiber sensors not just in terms of their capability for process monitoring tasks but also for a condition monitoring of the composite afterwards. The use of FBG sensors for Structural Health Monitoring (SHM) of fiber-reinforced composites is well established yet and their potential has been shown in numerous investigations ${ }^{9-13}$. The additional use of the signal response of the same 
optical fiber sensors during the processing of the composite part in terms of process control can be seen as a relevant added benefit. Therefore, the use of the FBG strain response in terms of cure monitoring in Resin Transfer Molding (RTM) processes is investigated within this study.

The application of FBG sensors for in-situ data acquisition in LCM processes was focused in several previous studies ${ }^{14-20}$, primary with the aim to investigate correlations of the signal response with the resin cure state, to measure the coefficient of thermal expansion, to detect process induced residual strains in the final part or to prepare the sensor integrated composite for subsequent SHM purposes. In the majority of the studies the strain responses of the FBG sensors are mainly affected by temperature changes, due to external heat or cool cycles or exothermal reaction heat. In the present study, we focus on the strain development based on the chemical transition of the polymer from liquid to solid and analyze the capabilities for providing online information of the actual cure state during RTM processing.

Within the studies from Harsch et al ${ }^{21-24}$ FBG sensors played a major role in the analysis of cureinduced stresses in filled and unfilled epoxy systems. A fiber optical sensor method was developed based on a laboratory test setup to measure the strain development in the crosslinking polymer. Antonucci et al ${ }^{25}$ did similar investigations to analyze the cure-induced strain build-up inside an epoxy resin using FBG sensors. A good agreement between the acquired strain data and accompanied simulation results was observed. Another study with an abstracting experimental setup was conducted by Karalekas et al ${ }^{26}$ who investigated residual stresses and strains inside a cylindrical epoxy sample with embedded FBG sensors resulting from subsequent thermal cycles. These studies demonstrated the capability of fiber optic sensor in providing valuable information on the resins cure state.

The use of FBG sensors for RTM production monitoring was part of the work of Chiesura et al 17,16. Within these studies FBG sensors were embedded in exemplary RTM processed parts and used as in-situ sensors for process monitoring during the injection, the curing and the post-cure processes. The capability for detecting the resin flow during injection, temperature changes and residual strains inside the part were shown, but a reliable tracking of the cure state based on the FBG signal could not be provided due to inconsistencies of the strain responses. 
The present study examines, whether the cure induced strain measurement with FBG sensors within an RTM process can be conducted in a manner to give valuable in-situ feedback of the actual cure state of the resin system under process conditions. This was done with particular attention to the reproducibility of the signal behavior as well as to their generality by varying the isothermal cure temperature within our series of RTM experiments.

\section{EXPERIMENTAL}

\subsection{Materials}

The reinforcement fabric used for the composite manufacturing was a woven flax-fiber textile (Biotex Flax $400 \mathrm{~g} / \mathrm{m}^{2}$ 2/2 Twill) supplied by Composites Evolution (Chesterfield, UK). The matrix system for the RTM test series was a two-component diglycidylether of bisphenol A (DGEBA) epoxy system for infusion processes (Epinal LR 80-A2.01) provided by bto-epoxy $\mathrm{GmbH}$ (Amstetten, Austria). With the given diamine-based hardener (Epinal LH 80-B2.00) the resin system provides a pot life of $60 \mathrm{~min}$ at room temperature and cures within a recommended temperature range between $25^{\circ} \mathrm{C}$ and $90{ }^{\circ} \mathrm{C}$. The mixing ratio for the resin and hardener component is 100:25 by weight according to the manufacturer specification.

\subsection{Sensors}

Sylex FFA-01 FBG sensors (Sylex, Bratislava, Slovakia) were used for the strain measurement which provides a measurable strain range of $\pm 3000 \mu \varepsilon$. The sensor configuration was chosen with a total fiber length of $3 \mathrm{~m}$, a single Bragg grating located in the middle of the optical fiber and a defined wavelength within the range between $1510 \mathrm{~nm}$ and $1590 \mathrm{~nm}$. In general, there is also the possibility to apply multiple Bragg gratings in an array design along the optical fiber to enable the strain measurement at different positions at once. The sensors used for the test series are usually used for direct gluing on top of the measured surface. According to the supplier's recommendations epoxy and cyanoacrylate adhesives systems are suitable for the mounting of the polyimide coated optical fiber. In the present case the embedding of the fiber in the epoxy resin system was done without any pretreatment of the fiber surface, since pretests with stripped 
off coatings around the Bragg gratings did not show any quality improvements of the measured strain data but significantly increased the probability for sensor failures. The active Bragg grating length in the present case is $<5 \mathrm{~mm}$. The data acquisition was conducted by a Sylex S-Line Scan 800 interrogator with an acquisition rate of $1 \mathrm{~Hz}$.

Additional temperature measurements inside the mold were done using the data acquisition system TC-08 from Omega Engineering (Deckenpfronn, Germany) in combination with type-K thermocouples (TT-KI-40) with outer wire dimensions of $0.6 \mathrm{~mm} \times 1.0 \mathrm{~mm}$.

\subsection{RTM process setup}

The woven textile layers were cut and dried in a convection oven (Model FDL 115, Binder GmbH, Germany) at $120{ }^{\circ} \mathrm{C}$ for approximately $2 \mathrm{~h}$ directly before the processing. Afterwards, the textile stack, consisting six individual layers, was positioned in the preheated RTM mold with a cavity dimension of $270 \mathrm{~mm} \times 270 \mathrm{~mm} \times 4 \mathrm{~mm}$. In addition, the FBG sensors and additional thermocouples were installed, which is described in detail in the following section. The mold carrier used for the RTM test series was a laboratory press (LZT-OK-80-SO) from Langzauner (Lambrechten, Austria). After the preparation of the preform and the sensors, the two components of the thermoset epoxy-amine system were mixed and subsequently degassed for approximately 15 min using a desiccator and a vacuum pressure of 50 mbar at room temperature. The injection of the resin was done using a pressure pot with an injection pressure of 2 bar. The RTM mold provides a resin distribution channel across the cavity width at the inlet side and two vents at the opposite side, which were open during the resin injection. After the mold was filled and excessive resin reached the outlet, the venting tubes were closed and a post pressure of 2 bar was maintained by the pressure pot during the curing process. The injection and the curing step were performed under isothermal conditions at $50{ }^{\circ} \mathrm{C}$ and $70{ }^{\circ} \mathrm{C}$, respectively. After a suitable cure state was reached, the composite plate with the integrated FBG sensors was demolded. During the manufacturing process, starting with the closing of the mold until the demolding step, the signals of the FBG sensors and additional thermocouples were recorded using an acquisition rate of $1 \mathrm{~Hz}$. 


\subsection{Approaches for the FBG sensor integration}

Particular attention was paid regarding to the FBG sensor location inside the mold and the local surrounding next to the sensitive Bragg grating element. Three different methods were evaluated, which are illustrated in Fig. 1. In the first approach (Approach A), the FBG sensor was placed inside the preform between the $5^{\text {th }}$ and $6^{\text {th }}$ layer of the laminate and represents the most common way for embedding optical fibers as an intrinsic part of the composite structure. To avoid any preloads on the sensor due to compaction mechanisms during the mold closure and to examine the influence of the textile reinforcement on the strain development, the FBG was also positioned in locations, which were not directly in contact with the reinforcing textile. In approach B the textile preform was prepared with round punch-outs in which the Bragg grating was positioned.

Those spaces were filled with neat resin material during the injection process.

(a)

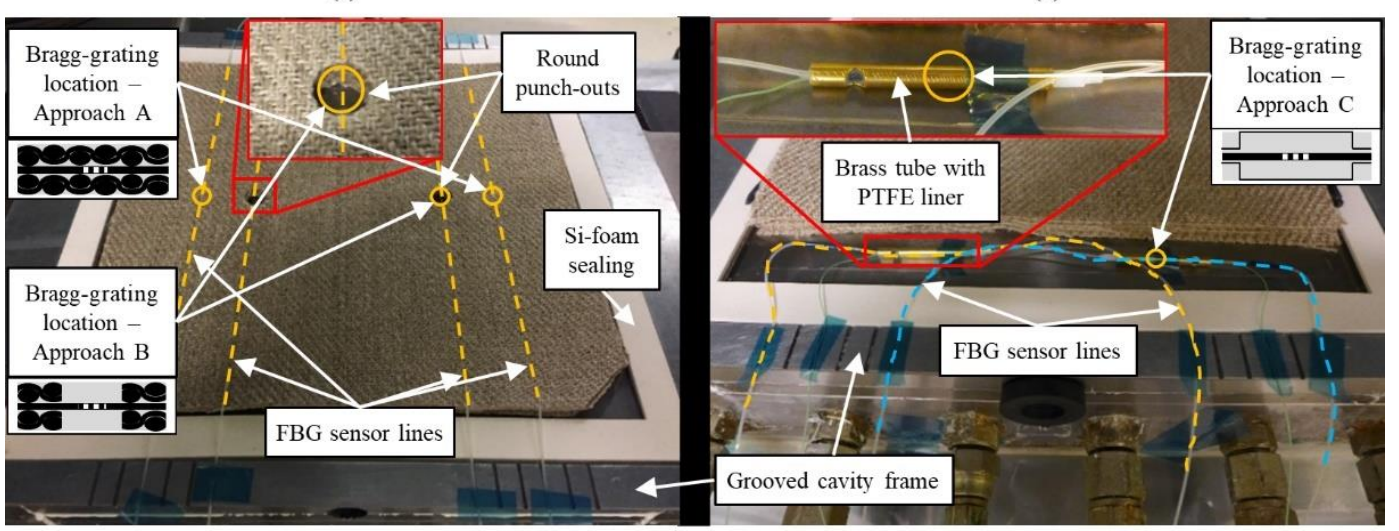

Fig. 1: View into the RTM mold cavity: Three different approaches for the installation of the FBG sensor (Approach A and B in experiment setup (a), Approach C in experiment setup (b)).

The third approach (Approach C) goes one step further with the objective to obtain better control of the local surrounding next to the Bragg grating location. Therefore, the sensitive part of the optical fiber was capsuled in a small brass tube with an integrated PTFE liner. In Fig. 2 the corresponding setup is depicted schematically. During the injection process, the empty space of the tube-shaped control volume was filled with resin, which entered the tube through the inlet hole and flowed along the resin outlet tube. After excessive resin reached the end of the outlet tube, which was located outside of the mold, the tube was clamped with a hose clamp. This sensor 
design aims to obtain an improved reproducibility of the cure-induced strain development by providing a defined sensor position inside a controlled resin volume and a non-adhesive PTFE liner as contact surface for the thermoset material with the immediate surrounding. A type-K thermocouple was positioned inside the control volume to check the compliance of isothermal conditions during cure.

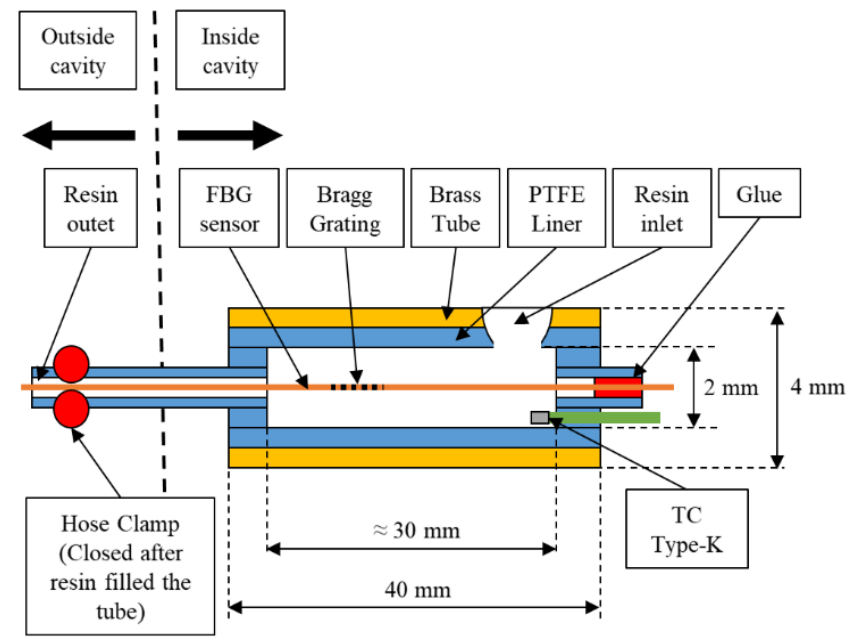

Fig. 2: Schematics of the FBG sensor design of approach C.

In the course of the RTM process preparation, the optical fibers and additional thermocouple wires were guided into and out of the mold, using a metal cavity frame with $1 \mathrm{~mm} \times 1 \mathrm{~mm}$ sized grooves, as can be seen in Fig. 1. The sealing was maintained by using two silicone foam cuttings between the grooved frame and the cavity. To protect the FBG sensor from any damage a PTFE tube was used to cover the optical fiber where it is not an intrinsic part of the composite plate. The FBG sensor strain was set to zero after they were installed. Afterwards the mold was closed to, which led to the compaction of the textile preform, and the resin was injected.

\section{CURE CHARACTERIZATION OF THE EPOXY-AMINE SYSTEM}

To get detailed insight regarding the actual properties of the thermoset matrix system during the cure process, rheometric and calorimetric measurements were carried out and analyzed. The results allow the comparison of the FBG sensor data, acquired during the process monitoring, with the associated cure degree and characteristic points associated with the sol-gel transition. 


\subsection{Rheological analysis}

Rheological measurements were done on an MCR 501 rheometer (Anton Paar GmbH, Graz, Austria) using a parallel plate configuration with a plate diameter of $50 \mathrm{~mm}$ and a gap height in the range between $0.727 \mathrm{~mm}$ and $1.597 \mathrm{~mm}$. In isothermal conditions, an oscillatory mode was used with an angular frequency of $10 \mathrm{rad} / \mathrm{s}$ and a strain amplitude of $30 \%$. Temperatures of $50{ }^{\circ} \mathrm{C}$ and $70{ }^{\circ} \mathrm{C}$ were used, respectively, to provide analogous conditions compared to the process temperatures used in the RTM experiments. Additional measurements at $55^{\circ} \mathrm{C}, 60{ }^{\circ} \mathrm{C}$ and $65{ }^{\circ} \mathrm{C}$ allow an accurate evaluation of the temperature dependent behavior. Due to the variety of existing approaches to define the gelation point of a curing thermoset system based on rheological measurement data, special attention was put on the selection procedure in this study. Therefore, the most common criteria, which can be found in literature, were applied and discussed.

Based on the resulting curve progressions for the storage modulus $G^{\prime}$, the loss modulus $G^{\prime \prime}$, the loss factor $\tan \delta$ or the normal force $F_{n}$, the following criteria for the determination of the gelation point has been established:

- (i) Intersection point of the storage modulus $G^{\prime}$ and the loss modulus $G^{\prime \prime 27,28}$

- (ii) Peak of the curve of the loss factor $\tan \delta^{29-31}$

- (iii) Onset point of the increase of the storage modulus $G^{\prime}{ }^{32}$

- (iv) Onset point of the normal force drop $F_{n}{ }^{22,33}$

- Point of $\tan \delta$ characterized by frequency independence 34,33

With the exception of the latter, which could not be applied due to the defined test procedure using a fixed frequency, the detected times for the gel points depending on the criteria (i) to (iv) are listed in Table 1.

Table 1: Gelation times depending on different determination criteria. (Time values in brackets were detected after a sudden signal drop appeared during test)

\begin{tabular}{ccccccc}
\hline & & \multicolumn{5}{c}{ Cure Temperature $\left[{ }^{\circ} \mathrm{C}\right]$} \\
& Criteria & 50 & 55 & 60 & 65 & 70 \\
\hline \multirow{2}{*}{ Gelation } & (i) & $(87.6)$ & $(64.4)$ & 44.7 & 33.6 & 23.9 \\
time & (ii) & 60.0 & 45.1 & 33.8 & 26.6 & 19.9 \\
{$[$ min $]$} & (iii) & 61.4 & 46.0 & 34.4 & 27.1 & 20.3 \\
& (iv) & 83.3 & 61.3 & 43.0 & 32.5 & 23.5 \\
\hline
\end{tabular}


The corresponding curves for the storage modulus $G^{\prime}$, the loss modulus $G^{\prime \prime}$, the loss factor $\tan \delta$, the normal force $F_{n}$ and the dynamic viscosity $\eta_{d y n}$ are depicted in Fig. 3, exemplarily for an isothermal cure temperatures of $50{ }^{\circ} \mathrm{C}$. The vertical lines mark the evaluated time points for the gelation based on the underlying criteria. The experiments at $50{ }^{\circ} \mathrm{C}$ and $55^{\circ} \mathrm{C}$ showed a sudden signal drop after $87.4 \mathrm{~min}$ and $62.6 \mathrm{~min}$, respectively, before the $G^{\prime}-G^{\prime \prime}$ crossover point was reached.
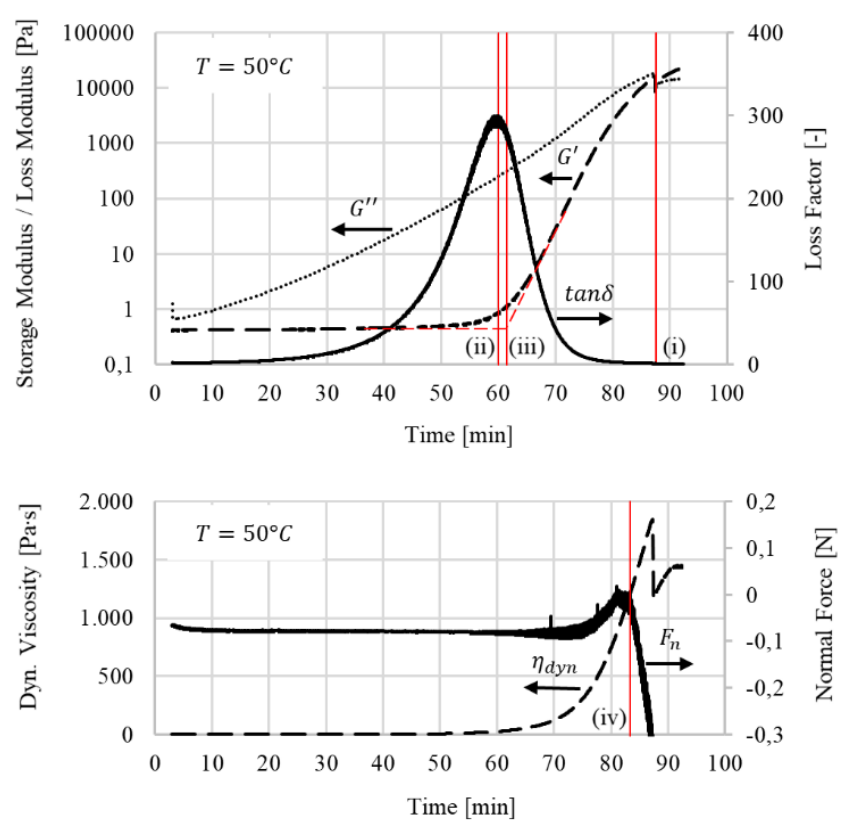

Fig. 3: Rheological measurement results for an isothermal cure temperature of $50{ }^{\circ} \mathrm{C}$ and detected gelation times based on criteria (i) to (iv).

The comparison of the time values indicates that the gelation times based on criteria (ii) and (iii) result in an earlier time range than the time values based on criteria (i) and (iv) within the tested temperature range. The shortest gelation times for all tested temperatures result from the $\tan \delta$ peak criterion (ii), while the highest values correspond to the $G^{\prime}-G^{\prime \prime}$-intersection criterion (i).

\subsection{Dynamic Scanning Calorimetry (DSC) analysis}

DSC experiments were carried out on a Q2000 device from TA Instruments (New Castle, Delaware, USA). An isothermal test approach at $50{ }^{\circ} \mathrm{C}$ and $70{ }^{\circ} \mathrm{C}$ was chosen, to represent the 
cure situation in the RTM process. The measurement times were set to $24 \mathrm{~h}$ and $14 \mathrm{~h}$ for the isothermal cure at $50{ }^{\circ} \mathrm{C}$ and $70{ }^{\circ} \mathrm{C}$, respectively. All measurements were conducted under nitrogen atmosphere using a $\mathrm{N}_{2}$ gas flow of $50 \mathrm{ml} / \mathrm{min}$. Based on the corresponding heat flow, the cure degree over time was evaluated using Equation (1):

$$
\alpha=\frac{\Delta H(t)}{\Delta H_{T}}
$$

where $\Delta H_{T}$ is the total reaction heat and $\Delta H(t)$ the partial reaction heat from experiment start until time $t$. The total reaction heat was evaluated based on the results from isothermal measurement at $50{ }^{\circ} \mathrm{C}$ and a subsequent dynamic heat-cool-heat cycle within the temperature range from $25^{\circ} \mathrm{C}$ to $250{ }^{\circ} \mathrm{C}$ and a ramp of $10^{\circ} \mathrm{C} / \mathrm{min}$ to calculate the residual reaction heat of the sample. The sum of both parts were then defined as the total reaction heat $\Delta H_{T}$ as follows in Equation (2):

$$
\Delta H_{T}=\Delta H_{\text {iso }}+\Delta H_{\text {res }}
$$

The corresponding values were $\Delta H_{i s o, 50^{\circ} \mathrm{C} / 24 \mathrm{~h}}=450.3 \mathrm{~J} / \mathrm{g}$ and $\Delta H_{r e s, 50^{\circ} \mathrm{C} / 24 \mathrm{~h}}=26.1 \mathrm{~J} / \mathrm{g}$. The isothermal reaction heat at $70{ }^{\circ} \mathrm{C}$ was $\Delta H_{i s o, 70^{\circ} \mathrm{C} / 14 \mathrm{~h}}=472.6 \mathrm{~J} / \mathrm{g}$. Based on these values the final cure degrees after the isothermal measurements were determined to $94.5 \%$ and $99.2 \%$ for $50{ }^{\circ} \mathrm{C}$ and $70{ }^{\circ} \mathrm{C}$, respectively. The diagram in Fig. 4 shows the specific heat flow over time under isothermal conditions and the corresponding cure degree conversion for $50{ }^{\circ} \mathrm{C}$ and $70{ }^{\circ} \mathrm{C}$, respectively. The heat flow decreases asymptotically to values close to zero at times long before the total experiment time. $99 \%$ of the final cure degree was reached after $8.4 \mathrm{~h}$ and $6.5 \mathrm{~h}$ during the DSC measurement at $50^{\circ} \mathrm{C}$ and $70^{\circ} \mathrm{C}$, respectively. Therefore, it can be assumed that the practically achievable maximal degree of cure, corresponding to the specific cure temperature, was reached at the experiment end after $24 \mathrm{~h}\left(50{ }^{\circ} \mathrm{C}\right)$ and $14 \mathrm{~h}\left(70{ }^{\circ} \mathrm{C}\right)$, respectively. 


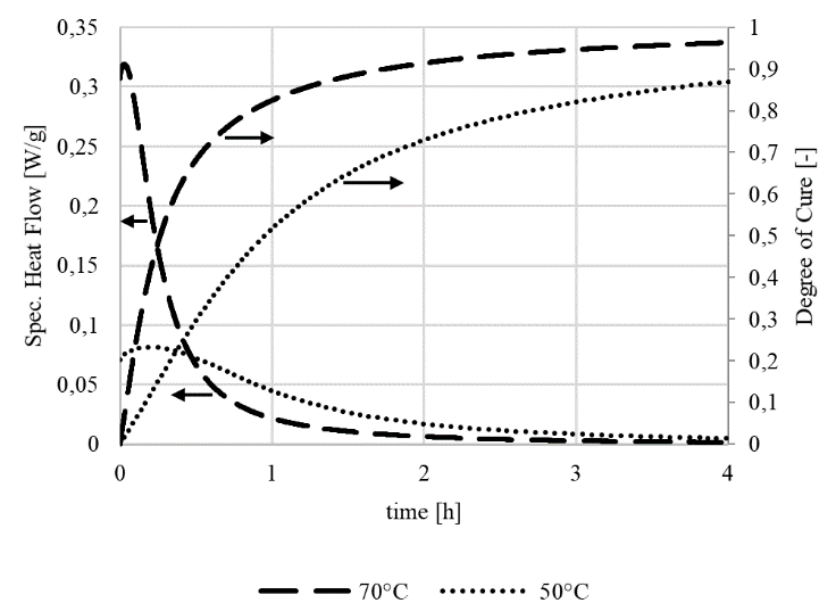

Fig. 4: DSC measurements: Specific heat flow and corresponding cure conversion for isothermal cure at $50{ }^{\circ} \mathrm{C}$ and $70{ }^{\circ} \mathrm{C}$, respectively.

\subsection{Discussion of the considered gel point criteria and corresponding gelation times}

Since the time range of detected gelation times based on the used criteria is remarkable large, particular attention was put on the selection of the most representative criterion and time values, correlating with defined conditions at the gel point. In general the gel point marks the transition of a material from liquid to solid (sol-gel-transition) and correlates with the growth of a connected molecular structure ${ }^{35}$. In relation to a curing thermoset polymer system, that means the initial formation of an infinite polymer network as a consequence of the chemical cross-linking reaction 35,36. By definition, the degree of conversion at the gel point is constant for a thermoset polymer system, independent of the cure temperature ${ }^{37}$. That property was used in the present work by evaluating the cure degrees correlating to the different gelation times. Fig. 5a) depicts the cure degree values at the evaluated gelation times based on criteria (i) to (iv). The comparison shows a significant difference of the cure conversion at the gel point using the $\tan \delta$-peak criterion (ii) or the $G^{\prime}$-onset criterion (iii). The corresponding cure degrees are in the range of 52\% and 57\% for cure temperatures of $50^{\circ} \mathrm{C}$ and $70{ }^{\circ} \mathrm{C}$, respectively. A more constant degree of cure, independent from the cure temperature, results with the $G^{\prime}-G^{\prime \prime}$-intersection criterion (i) and especially with the $F_{n}$-drop criterion (iv). With the latter, the corresponding cure degrees at the gel point are in the range of $62 \%$. As a complement to the cure degree values, the evaluation of 
the corresponding dynamic viscosities at the gel points can be seen in Fig. 5b). While the dynamic viscosity corresponding to criteria (ii) and (iii) are in a range between $14 \mathrm{~Pa} \cdot \mathrm{s}$ and $31 \mathrm{~Pa} \cdot \mathrm{s}$, the gelation times based on criterion (iv) correspond with higher dynamic viscosity values from $1204 \mathrm{~Pa} \cdot \mathrm{s}$ at $50{ }^{\circ} \mathrm{C}$ to $309 \mathrm{~Pa} \cdot \mathrm{s}$ at $70{ }^{\circ} \mathrm{C}$ with a plausible temperature dependence. Due to the signal drop during the rheological measurements, as mentioned before, the dynamic viscosity for the rheological experiments at $50{ }^{\circ} \mathrm{C}$ and $55^{\circ} \mathrm{C}$ could not be evaluated for the $G^{\prime}$ - $G^{\prime \prime}$-intersection criterion (i).

(a)

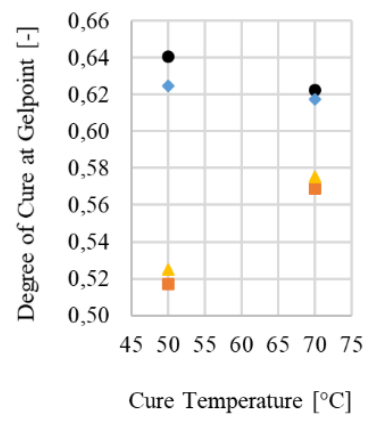

(b)

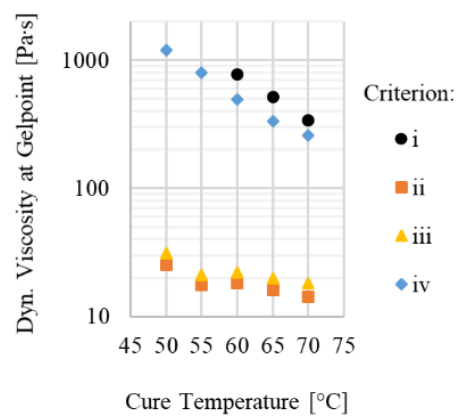

(c)

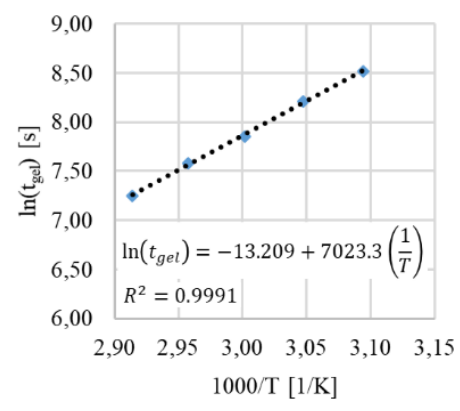

Fig. 5: Cure degree (a) and dynamic viscosity values (b) for the evaluated gelation times.

Arrhenius plot based on the results of criterion iv (c)

A comparison with former results based on DGEBA/diamine thermoset systems supports the validity of the $F_{n}$-drop criterion (iv) for the gel point detection. López et al ${ }^{38}$ studied the gelation and vitrification process at three different epoxy systems using dynamic mechanical analysis (DMA). The DGEBA epoxy resin with a cycloaliphatic diamine based hardener system $($ amine/epoxy ratio $=1)$ showed a mean cure conversion of $62.4 \%$ based on five measurements at $60,70,80,90$ and $100{ }^{\circ} \mathrm{C}$, but with a relatively high distribution of the single results in a range between $58 \%$ and $65 \%$. In the study of Cadenato et $\mathrm{l}^{30}$ a DGEBA epoxy system with an aromatic amine hardener was characterized and the cure degree at the gel conversion for isothermal cure between $50{ }^{\circ} \mathrm{C}$ and $105{ }^{\circ} \mathrm{C}$ was determined based on thermo mechanical analysis (TMA) and dynamic mechanical thermal analysis (DMTA) in combination with subsequent DSC tests. They determined a constant gel conversion of $0.62 \pm 0.03$ within the tested temperature range and confirmed with their results the isoconversional character of the gelation phenomenon. Núñez- 
Regueira et $\mathrm{l}^{39}$ also used a DGEBA epoxy resin with a metaxylylenediamine (m-XDA) curing agent for their characterization of the gelation process. Based on rheometric measurements the mean degree of conversion at the gel point was determined as 0.60 within the tested temperature range between $50{ }^{\circ} \mathrm{C}$ and $100{ }^{\circ} \mathrm{C}$. The theoretical value of the cure conversion at the gel-point based on the Flory theory is $57.7 \%$ in case of stochiometric DGEBA/diamine systems ${ }^{36,30}$. The slightly higher values which are determined experimentally can be explained by effects like different reactivities of the reactive groups and intramolecular ring formation, which are not considered in this theory ${ }^{30,40}$.

Due to the key criterion of an isoconversional character of the gelation process and supported by the validity check, that confirmed the plausibility of the cure degree at the gel point, the $F_{n}$-drop criterion (iv) can be stated as the most representative method for the detection of the gelation time, considered within this study. As might be expected, the time-temperature relationship of the gelation kinetics is in good agreement with the Arrhenius equation as can be seen from Fig. 5c). The corresponding activation energy is $58.8 \mathrm{~kJ} / \mathrm{mol}$.

\section{RESULTS AND DISCUSSION}

Fig. 6 shows the measured FBG strain signals during the RTM process with isothermal cure temperatures of $50{ }^{\circ} \mathrm{C}$ and $70{ }^{\circ} \mathrm{C}$, respectively. From top to bottom the strain curves belong to the FBG sensors installed regarding the above-mentioned approaches A, B and C, respectively. The injection starts at time zero and starts to saturate the textile reinforcement. After the resin reached the outlet, the venting tubes were clamped and the injection pressure of 2 bar at the inlet was maintained during the curing process. The signal drop of the strain data at $50{ }^{\circ} \mathrm{C}$ for approach $\mathrm{A}$ and $\mathrm{B}$ is due to the demolding process and subsequent temperature drop to room temperature, which was done after $9 \mathrm{~h}$ in this experiment. While it was aimed to record two FBG sensors in each experiment for each installation approach, two sensor failures along with a signal loss appeared within the two experiments at $70{ }^{\circ} \mathrm{C}$. Therefore, approach $\mathrm{A}$ and $\mathrm{C}$ at $70{ }^{\circ} \mathrm{C}$ are represented by just one signal curve, respectively. 

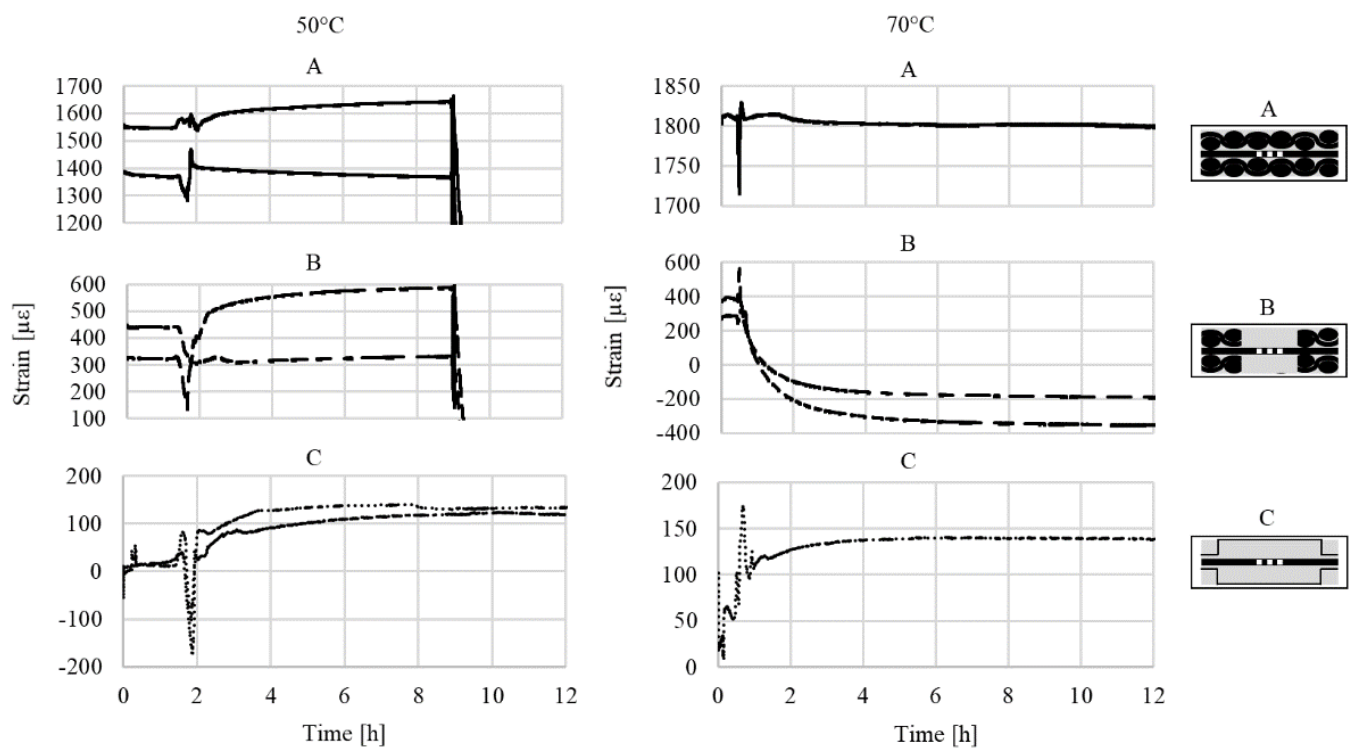

Fig. 6: FBG strain data during RTM process monitoring with isothermal cure conditions at $50{ }^{\circ} \mathrm{C}$ and $70{ }^{\circ} \mathrm{C}$, respectively.

Since the FBG sensor position of approach $\mathrm{C}$ is located right at the resin inlet, the detected strain signal during the initial phase was influenced by temperature changes, due to the temperature differences of the injected resin (RT) and the preheated mold $\left(50^{\circ} \mathrm{C}, 70^{\circ} \mathrm{C}\right)$. Therefore, the data was corrected according the provided temperature correction formula with the given calibration parameter for the corresponding FBG sensor. The actual temperature next to the Bragg grating element could be measured accurately with the integrated type-K thermocouple. The temperature development during the first minutes after injection are depicted in Fig. 7. The first contact with the resin is characterized by a temperature drop, which converged quickly within the first minutes with the target temperature. For approach $\mathrm{A}$ and $\mathrm{B}$ the situation is different, since the corresponding Bragg gratings are located in the middle of the mold and the resin flow path. The resin arrived that position during injection after about $60 \mathrm{sec}$ and $30 \mathrm{sec}$ in the $50{ }^{\circ} \mathrm{C}$ and $70{ }^{\circ} \mathrm{C}$ experiment, respectively. When the resin arrived the Bragg grating element it already reached a temperature close to the isothermal target temperature. Furthermore, exothermic reaction heat is not crucial in the present case. The resin temperature did not exceed a temperature of $71{ }^{\circ} \mathrm{C}$ inside the mold when cured at $70^{\circ} \mathrm{C}$. Therefore, a strain data correction due to temperature changes was not necessary for approach A and B. 


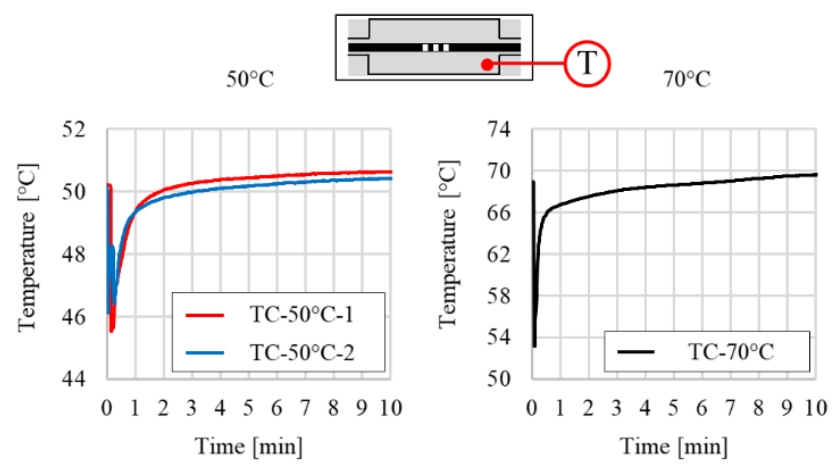

Fig. 7: Temperature development during the initial phase after resin injection measured with the integrated thermocouples of approach C.

As can be seen from the diagrams in Fig. 6 the curves show similar curve characteristics in the first phase of the cure reaction. After an initial time period with an almost constant strain progression the signal changes rapidly in tension or compression direction. This conspicuous strain decrease or raise appears in later times in case of a cure temperature of $50{ }^{\circ} \mathrm{C}$ compared to the experiments at $70{ }^{\circ} \mathrm{C}$. After a certain time period, which is characterized by alternating changes in tension and compression direction, the signal stabilizes again and shows in most cases a monotonous progression either in positive or negative direction. In some cases, this latter stage is interrupted by smaller signal steps, as can be seen in the bottom curve of approach B and in the two curves of approach $\mathrm{C}$ at $50{ }^{\circ} \mathrm{C}$.

The corresponding curves of approach A show the highest strain levels due to the applied strain during compaction. The Bragg grating is located between two layers of the textile stack and in direct contact with the fiber reinforcement. The nesting process between two textile layers during compaction is a dominant mechanism for woven fabrics ${ }^{41,42}$ and forces the optical sensor in between in a more undulated and tension loaded state. The curves show the before mentioned sudden strain change in the first stage but with further progression the behavior varies. In later times, the strain shows an increasing, decreasing or constant behavior. This unreproducible and unpredictable behavior was also present in the FBG strain curves from Chiesura ${ }^{17,16}$, who placed the Bragg gratings inside the reinforcing textile structure. Similar observations were made by Tsai et $a^{43}$, who concluded that the cure induced shrinkage inside a prepreg laminate could not be 
measured accurately with the embedded fiber optical sensor, due to the influence of the reinforcing fibers. Referred to our results, the undefined preloaded state after compaction and the influence of the reinforcement structure besides the grating could be the reason for the observed variation of the strain progression during cure.

The results based on approach B confirm the assumption of the crucial influence of uncontrollable boundary conditions next to the Bragg grating. While the strain curves based on the measurements at $50{ }^{\circ} \mathrm{C}$ show a progression in tension direction, the curves at $70{ }^{\circ} \mathrm{C}$ run asymptotically in the opposite direction. The preload caused by the textile compaction could be significantly reduced, but the reproducibility of the strain progression could not be achieved.

Approach $\mathrm{C}$ was conducted to improve the reproducibility of the cure-induced processes in close proximity of the Bragg grating element, by measuring the strain inside a capsuled controllable resin volume. Therefore, the corresponding measurements were not influenced by the textile compaction since the sensor is positioned inside a brass tube as described above. While a reproducible signal progression could not be achieved with the integration approaches A and B, the more controllable surrounding besides the Bragg-grating led in this case to a strain development in tension direction with an asymptotic behavior at later cure times in all measurements.

We assume that differences between the experiments, like locations of first detachments between the resin and the cavity surface and local inhomogeneities of the cure conversion during the solidification, determine the resulting local stress and strain conditions inside the cross-linking resin system, thus the acquired strain data measured by the FBG sensor. Although the crosslinking process in the epoxy system is associated with a chemical shrinkage, the cure-induced deformation can lead to elongation of the optical fiber due to deflections out of the initial fiber axis which lead to a tensional strain progression as observed in the majority of our measurements.

\subsection{FBG strain response near the gel point}

Detailed sections of the acquired strain data in early cure stages are shown in the diagrams of Fig.

8. The red vertical lines mark the evaluated gelation time based on the previously discussed $F_{n^{-}}$ 
drop criterion (iv) for both cure temperatures, respectively. As can be seen, the before mentioned characteristic strain changes appear right after the gelation state is reached. Little differences between the gelation time and the start of the signal change can be explained by a delayed cure reaction in the RTM experiments due to the time required for heating the matrix system from room temperature to the adjusted tool temperature during injection (see Fig. 7).

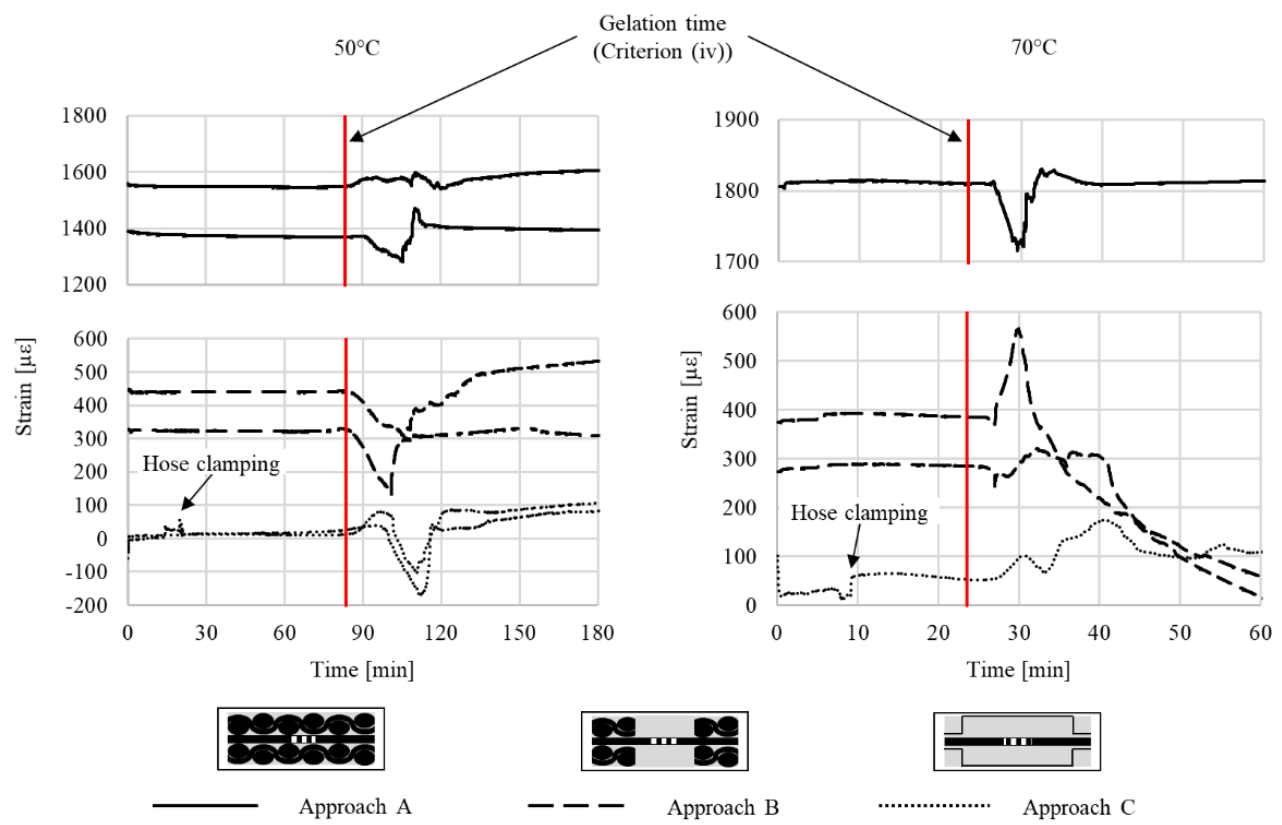

Fig. 8: FBG strain curves near the gel point at $50{ }^{\circ} \mathrm{C}$ and $70{ }^{\circ} \mathrm{C}$, respectively.

The sudden signal steps in the curves corresponding to approach $\mathrm{C}$ before the gelation time was reached, was caused by the manual closing of the PTFE tube with the hose clamp after the resin completely filled the sensor tube during injection (see Fig. 2).

The correlation between the sudden changes of the strain signal is evident. The used $F_{n}$-drop criterion (iv), as discussed above, represents physically the start of a significant load transduction by the resin system, since it defines a state of the cross-linked network which is capable to transfer loads through the material. If this characteristic state of cure is reached in the surrounding of the Bragg grating, the induced loads of the reacting polymer system lead to the observed behavior with pronounced strain changes. In this context, it can be stated that the FBG sensor, applied for the RTM process monitoring, is suitable to detect the gelation point of the thermoset during cure. 


\subsection{FBG strain response with further cure conversion}

In addition to the analysis of the strain signal in early cure stages during gelation, the capability of the FBG sensor response to predict the cure stage at later times is investigated. Since the results based on approach $\mathrm{C}$ shows the most reproducible tendency of the strain development over time for both cure temperatures, the corresponding measurements are used for the analysis. The acquired strain data over time are compared with the evaluated cure conversion based on the DSC analysis. For better comparison the data were normalized using the corresponding initial values at time zero (normalized value $=0$ ) and the values after $20 \mathrm{~h}$ and $12 \mathrm{~h}$ for $50^{\circ} \mathrm{C}$ and $70{ }^{\circ} \mathrm{C}$ cure temperature, respectively (normalized value $=1$ ).
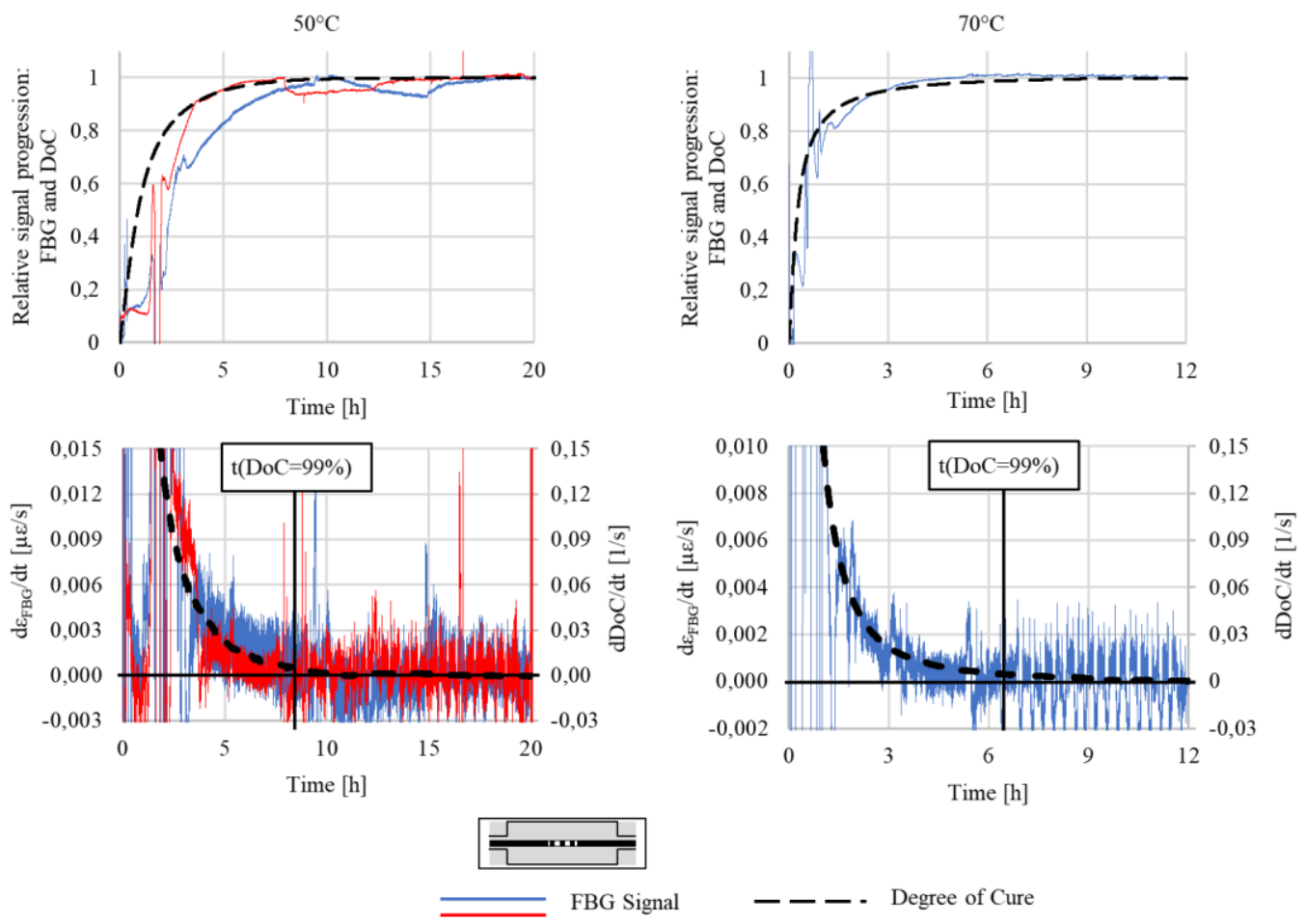

Degree of Cure

Fig. 9: Relative signal progresses and 1. derivations considering the FBG strain of approach C and the cure degree development over time at $50^{\circ} \mathrm{C}$ and $70^{\circ} \mathrm{C}$, respectively.

The signal progresses as well as the first derivations of the FBG strain and DoC over time are depicted in Fig. 9 for both cure temperatures, respectively. Due to the scatter of the strain data the derivation data were post processed using a Savitzky-Golay smoothing filter ${ }^{44}$ with a polynomial order of 3 and a window of 10 minutes or 600 data points. 
It can be seen that the asymptotic behavior of the FBG strain signals after passing the turbulent gelation-vitrification phase is in direct correlation with the cure state defined by the degree of cure of the epoxy-amine system. Nevertheless, it is obvious that apparent influences still disturb the cure-induced strain development, as can be seen from the pronounced deviations of the FBG strain curves at $50{ }^{\circ} \mathrm{C}$ cure temperature even at later times. The strain curve at $70{ }^{\circ} \mathrm{C}$ shows less disturbances and represents well the state of the matrix system compared with the given cure conversion over time. Nevertheless, the derivation curves reveal the potentials to use the strain signals to evaluate characteristic time points correlation with a higher degree of cure, for example to define a final cure stage for demolding. Using the asymptotic characteristics, a strain rate close to zero is then in relation to a high degree of cross-linking of the polymer. The diagrams contain exemplarily the time points which corresponds to a conversion rate of $99 \%$ with respect to the final cure degree for both temperatures, respectively. Beyond that time points the FBG strain tends to remain constant. Based on the required FBG data a quantitative reliable analysis, that can be applied as online monitoring, requires a higher consistency of the strain response. Therefore, further work should be conducted to analyze suitable conditions to ensure a high reproducibility of the measurement data with minimal disturbance. A significant improvement was achieved with the positioning of the sensor inside a controlled resin volume. The acting boundary conditions, especially the sensor-resin interface and the contact surfaces between and resin and adjacent components should be explored in future to further increase the reliability.

Based on our results we can state that under suitable conditions the FBG sensor gives valuable feedback in connection with the cure state even in advanced cure stages. Future investigations should be adapted to optimize the approach considering the sensor preparation, installation and online data processing. 


\section{CONCLUSION}

In this study, FBG sensors were used within the scope of cure monitoring in RTM processes. Particular attention was paid on the preparation and location of the Bragg grating location inside the mold cavity. Three different approaches: Inside the reinforcing structure (A), inside a neat resin location (B) and inside a controlled resin volume (C), were tested and analyzed. The experiments were conducted under isothermal cure conditions at $50{ }^{\circ} \mathrm{C}$ and $70{ }^{\circ} \mathrm{C}$, respectively. The accompanying variation of the cure rate allowed us to verify the reproducibility and reliability of the acquired strain data and their correlation with the actual cure state. We can state, that the FBG sensor response enables the detection of the characteristic gel point of the thermoset epoxyamine system during the conversion from liquid to glassy state. Therefore, it can be concluded that the strain detection inside the curing resin using FBG sensors delivers valuable information and enables an in-situ feedback of the actual cure state of the matrix system in that early cure stages. With increasing curing times, the reproducibility of the FBG strain progression and thus the correlation between the cure degree and the strain response, significantly depends on the location of the Bragg grating inside the process. The highest reliability was achieved with the Bragg grating located inside a tube-shaped resin volume (approach C). We expect that further optimizations of the sensor design and installation, which provides an even better control of the boundary conditions in the near surrounding of the sensitive Bragg grating, will lead to significantly better reproducibility of the FBG strain signal. If the FBG sensor with multiple Bragg gratings along the optical fiber is also used as integrated sensor inside the composite structure and combined with a structural health monitoring during its service life, the full potential of this fiberoptical sensor technology can be exhausted. 


\section{Acknowledgements}

Gergely Hegedüs, Gábor Szebényi, Tamás Tábi and Tibor Czigany acknowledge the support by the National Research, Development and Innovation Office, Hungary [Project nr. 2017-2.2.4TÉT-AT-2017-00011]. Yannick Blößl and Ralf Schledjewski kindly acknowledge the financial support received in frame of the mobility project [Project nr. HU09 2018] from the Federal Ministry of Science, Research and Economy (BMWFW) in Austria and administrated by the Austrian Agency for International Cooperation in Education \& Research (OEAD). This work is part of the project "Reliable and Sustainable composite production for Biobased Components", funded by the Austrian Ministry for Transport, Innovation and Technology (BMVIT) in frame of the program "Produktion der Zukunft" [Contract no. 858688]. 


\section{References}

1. Rudd CD, Kendall KN and Long AC. Liquid moulding technology: A guide to RTM, SRIM and related composites processing techniques. Cambridge: Woodhead, 1996.

2. Konstantopoulos S, Hueber C, Antoniadis I, et al. Liquid composite molding reproducibility in real-world production of fiber reinforced polymeric composites: a review of challenges and solutions. Advanced Manufacturing: Polymer \& Composites Science 2019; 5: 85-99.

3. Konstantopoulos S, Fauster E and Schledjewski R. Monitoring the production of FRP composites: A review of in-line sensing methods. Express Polym. Lett. 2014; 8: 823-840.

4. Mulligan DR. Cure monitoring for composites and adhesives. Shropshire, United Kingdom: Rapra Technology Limited, 2003.

5. Ferdinand P, Magne S, Dewynter-Marty V, et al. Applications of Fiber Bragg Grating Sensors in the Composite Industry. MRS Bull. 2002; 27: 400-407.

6. Doyle C, Martin A, Liu T, et al. In-situ process and condition monitoring of advanced fibrereinforced composite materials using optical fibre sensors. Smart Mater. Struct. 1998; 7: $145-158$.

7. Handerek VA. Chapter 10: Fiber gratings: principles, fabrication and properties. In: Grattan KTV and Meggitt BT (eds) Optical Fiber Sensor Technology: Devices and Technology. Boston, MA: Springer US, 1998.

8. Rao Y-J. Chapter 11: Fiber Bragg grating sensors: principles and applications. In: Grattan KTV and Meggitt BT (eds) Optical Fiber Sensor Technology: Devices and Technology. Boston, MA: Springer US, 1998.

9. Baere I de, Luyckx G, Voet E, et al. On the feasibility of optical fibre sensors for strain monitoring in thermoplastic composites under fatigue loading conditions. Optics and Lasers in Engineering 2009; 47: 403-411.

10. Zhu Q, Xu C and Yang G. Experimental research on damage detecting in composite materials with FBG sensors under low frequency cycling. International Journal of Fatigue 2017; 101: 61-66. 
11. Shen W, Yan R, Xu L, et al. Application study on FBG sensor applied to hull structural health monitoring. Optik 2015; 126: 1499-1504.

12. Liu T and Fernando GF. The application of optical fiber sensors in advanced fiber reinforced composites. Part 3. Strain, temperature and health monitoring. In: Grattan KTV and Meggitt BT (eds) Optical Fiber Sensor Technology: Applications and Systems. Boston, MA: Springer US, 1999.

13. Leng $\mathrm{J}$ and Asundi A. Structural health monitoring of smart composite materials by using EFPI and FBG sensors. Sensors and Actuators A: Physical 2003; 103: 330-340.

14. Murukeshan VM, Chan PY, Ong LS, et al. Cure monitoring of smart composites using Fiber Bragg Grating based embedded sensors. Sensors and Actuators A: Physical 2000; 79: 153161.

15. Sampath U, Kim H, Kim D-g, et al. In-Situ Cure Monitoring of Wind Turbine Blades by Using Fiber Bragg Grating Sensors and Fresnel Reflection Measurement. Sensors (Basel) 2015; 15: 18229-18238.

16. Chiesura G. Interaction of Composites with Various Types of Embedded Sensors and Their Use for Cure and Fatigue Life Monitoring. Dissertation, Ghent University. Zwijnaarde, Belgium, 2017.

17. Chiesura G, Lamberti A, Yang Y, et al. RTM Production Monitoring of the A380 Hinge Arm Droop Nose Mechanism: A Multi-Sensor Approach. Sensors (Basel) 2016; 16.

18. Eum SH, Kageyama K, Murayama H, et al. Structural health monitoring using fiber optic distributed sensors for vacuum-assisted resin transfer molding. Smart Mater. Struct. 2007; 16: $2627-2635$.

19. Canal LP, Benavente M, Hausmann M, et al. Process-induced strains in RTM processing of polyurethane/carbon composites. Composites Part A: Applied Science and Manufacturing 2015; 78: 264-273.

20. Khoun L, Oliveira R de, Michaud V, et al. Investigation of process-induced strains development by fibre Bragg grating sensors in resin transfer moulded composites. Composites Part A: Applied Science and Manufacturing 2011; 42: 274-282. 
21. Harsch M, Karger-Kocsis J and Herzog F. Strain development in a filled epoxy resin curing under constrained and unconstrained conditions as assessed by Fibre Bragg Grating sensors. Express Polym. Lett. 2007; 1: 226-231.

22. Harsch M, Herzog F and Karger-Kocsis J. Cure-induced Normal Force Development in Unfilled and Filled Epoxy Resins. Journal of Composite Materials 2008; 42: 2299-2309.

23. Harsch M, Karger-Kocsis J and Herzog F. Monitoring of cure-induced strain of an epoxy resin by fiber Bragg grating sensor. J. Appl. Polym. Sci. 2008; 107: 719-725.

24. Harsch M, Karger-Kocsis J and Herzog F. Influence of Cure Regime on the Strain Development in an Epoxy Resin as Monitored by a Fiber Bragg Grating Sensor. Macromol. Mater. Eng. 2007; 292: 474-483.

25. Antonucci V, Cusano A, Giordano M, et al. Cure-induced residual strain build-up in a thermoset resin. Composites Part A: Applied Science and Manufacturing 2006; 37: 592601.

26. Karalekas D, Cugnoni J and Botsis J. Monitoring of process induced strains in a single fibre composite using FBG sensor: A methodological study. Composites Part A: Applied Science and Manufacturing 2008; 39: 1118-1127.

27. Shah DU and Schubel PJ. Evaluation of cure shrinkage measurement techniques for thermosetting resins. Polymer Testing 2010; 29: 629-639.

28. Costa ML, Botelho EC, Paiva JMFd, et al. Characterization of cure of carbon/epoxy prepreg used in aerospace field. Polymer 2005; 8: 317-322.

29. Hayaty M, Beheshty MH and Esfandeh M. A new approach for determination of gel time of a glass/epoxy prepreg. J. Appl. Polym. Sci. 2011; 120: 1483-1489.

30. Cadenato A, Salla JM, Ramis X, et al. Determination of gel and vitrification times of thermoset curing process by means of TMA, DMTA and DSC techniques. Journal of Thermal Analysis 1997; 49: 269-279.

31. Bilyeu B, Brostow W and Menard KP. Separation of gelation from vitrification in curing of a fiber-reinforced epoxy composite. Polym Compos 2002; 23: 1111-1119. 
32. Laza JM, Julian CA, Larrauri E, et al. Thermal scanning rheometer analysis of curing kinetic of an epoxy resin: 2. An amine as curing agent. Polymer 1999; 40: 35-45.

33. Martínez-Miranda MR, García-Martínez V and Gude MR. Gel point determination of a thermoset prepreg by means of rheology. Polymer Testing 2019; 78: 105950.

34. Lange J, Altmann N, Kelly CT, et al. Understanding vitrification during cure of epoxy resins using dynamic scanning calorimetry and rheological techniques. Polymer 2000; 41: 59495955.

35. Herman F. Mark. Encyclopedia of polymer science and technology. 3. ed. Hoboken, N.J.: Wiley, 2003.

36. Flory PJ. Principles of polymer chemistry. 19. print. Ithaca, NY: Cornell Univ. Press, ca. 2006.

37. Menczel JD and Prime RB. Thermal analysis in polymers. Oxford: Wiley, 2009.

38. López J, Ramírez C, Torres A, et al. Isothermal curing by dynamic mechanical analysis of three epoxy resin systems: Gelation and vitrification. J. Appl. Polym. Sci. 2002; 83: 78-85.

39. Núñez-Regueira L, Gracia-Fernández CA and Gómez-Barreiro S. Use of rheology, dielectric analysis and differential scanning calorimetry for gel time determination of a thermoset. Polymer 2005; 46: 5979-5985.

40. Flory PJ. Molecular Size Distribution in Three Dimensional Polymers. I. Gelation 1. J. Am. Chem. Soc. 1941; 63: 3083-3090.

41. Shah DU and Clifford MJ. Chapter 4: Compaction, permeability and flow simulation for liquid composite moulding of natural fibre composites. In: Salit MS, Jawaid M, Yusoff NB, et al. (eds) Manufacturing of Natural Fibre Reinforced Polymer Composites. Cham: Springer International Publishing, 2015.

42. Lomov SV, Verpoest I, Peeters T, et al. Nesting in textile laminates: geometrical modelling of the laminate. Composites Science and Technology 2003; 63: 993-1007.

43. Tsai J-T, Dustin JS and Mansson J-A. Cure strain monitoring in composite laminates with distributed optical sensor. Composites Part A: Applied Science and Manufacturing 2019; 125: 105503 . 
44. Savitzky A and Golay MJE. Smoothing and Differentiation of Data by Simplified Least Squares Procedures. Anal. Chem. 1964; 36: 1627-1639. 